\section{Study of brucellosis in serum of camels in southeast of Iran}

\author{
Ahmad Rafieipour, Nemat Ziaei \\ Department of Animal Science, Faculty \\ of Agriculture, University of Jiroft, Iran
}

\section{Abstract}

This study was carried out in the town of Qalegange, located in southeast of Iran, home of about 3816 camels. To study brucellosis in these animals, serological examinations including rose Bengal plat test (RBPT), MRT and 2ME were performed on 3502 camel's serum samples. Positive results were obtained in $245(7 \%), 163(4.66 \%)$ and $89(7.92 \%)$ camels thus tested, respectively. Twenty three percent of the positive camels were adult 2 years old, $36 \%$ three years old, $22 \%$ four years old, 17\% five years old and the remaining 3 percent were six years old. In the infected herds, abortion rates associated with the disease ranged from 10 to 39 percent. Other ailments observed associated with brucellosis were retention of the placenta, fetal death and mummification, delayed maturity and infertility. Recommendations for brucellosis control were given, in order to increase the awareness of shepherds, by suggesting regular testing, slaughtering of infected animals and vaccinations.

\section{Introduction}

Qalehgange is located in the province of Kerman in southeast Iran. The weather in this town is hot-arid (more than $40^{\circ} \mathrm{C}$ in summer) and its desert is suitable for rearing camels. About 3816 camels live in this area where cattle, sheep and goats also are intensively bred. Camel husbandry has a vital role in the life of a number of shepherd ethnic groups in Iran. The camel's ability to survive under harsh conditions made it possible to use marginal and desert ecosystems. ${ }^{1}$ Mayada et al. reported that Camels are highly susceptible to brucellosis caused by Brucella melitensis and Brucella abortus. ${ }^{2}$ Mohammed et al. stated that camel brucellosis was found to be well spread in the Ethiopia and the management practices and the tradition of using animal products warrant serious endanger of the society to Brucella infection. ${ }^{3}$ There is an increased awareness of role of camels as the main sources of milk and meat 4,5 and today in Iran, not only shepherds but also the urban population consumes camel's milk and meat. Brucellosis is transmitted from animals to humans by ingestion of raw milk, milk products, raw liver, and close contact with animals through breeding, birth, slaughtering and contaminated dust. ${ }^{6}$ In some countries including Iran, Iraq, Egypt, Kenya, Kuwait, Pakistan a high sero-prevalence of brucellosis in camels is reported. Brucellosis is the most important zoonosis in terms of human incidence: almost all human cases are acquired from animals, particularly camels, goats and sheep. ${ }^{7}$ Brucellosis in animals is caused by five recognized species of the genus Brucella. Four species commonly infect man: B. abortus, B. melitensis, B. suis and B. canis. ${ }^{8}$ Omar et al. reported that seroprevalence in camels (milk and serum samples). ${ }^{9}$ As we observed some cases of brucellosis in human beings in the area of Qalehgange, the aim of this study was to investigate the presence of brucellosis in camels and its impact on the livestock rearing system.

\section{Materials and Methods}

During a 4-month period in early 2009, 3502 serum samples were collected from indigenous camels throughout Qalehgange of Kerman of Iran. The distribution of camels in this area is shown in Table 1. Age, sex, clinical history, and date and place of sampling were recorded in a structured data collection form. Blood samples were drawn from 3502 camels and three serological tests for brucellosis were applied.

These were Rose Bengal Plate Test (RBPT), MRT and 2ME Test. The RBPT was used for all serum samples and both MRT and 2ME were performed on sera positive to RBPT.

\section{Results}

Positive test results were recorded in 245 (7\%) camels by RBPT, in 163 (4.66\%) camels by MRT and in 89 (7.92\%) camels by $2 \mathrm{ME}$. Twenty three percent of the positive camels were 2 -year-old, $36 \%$ three years old, $22 \%$ fouryear-old, $17 \%$ five-year-old and the remaining $3 \%$ were six-year-old. In infected herds, abortion rates associated with the disease ranged from $10-39 \%$ depending on the location. Other conditions caused by the disease were retention of placenta, fetal death and mummification, delayed maturity and infertility.

\section{Discussion}

Zoonoses continue to represent an important health hazard in most parts of the world, particularly in developing countries. ${ }^{10}$ Brucellosis is a classical zoonosis and the major
Correspondence: Dr. Nemat Ziaei, Department of Animal Science, Faculty of Agriculture, University of Jiroft, Iran.

Tel: +98.348.3260061- Fax: +98.348.3260065.

E-mail Address: Nemat.Ziaei@ujiroft.ac.ir

Key words: serology, camel, brucellosis, brucella spp., public health, qalehgange, Iran.

Acknowledgments: the authors would like to thanks Shahid Bahonar University of Kerman for funding the research project.

Received for publication: 15 September 2011. Accepted for publication: 17 October 2011.

This work is licensed under a Creative Commons Attribution NonCommercial 3.0 License (CC BYNC 3.0).

(C) Copyright A. Rafieipour and N. Ziaei, 2011 Licensee PAGEPress, Italy

Veterinary Science Development 2011; 1:e14 doi:10.4081/vsd.2011.e14

sources of infection remain contact with infected animals or the handling of carcasses. Less frequently it is acquired through food. Camels are not known to be primary hosts of Brucella organisms, but they are susceptible to both $B$. abortus and B. melitensis.11 Consequently, infection rate in camels depends upon the infection rate in primary hosts animals in contact with them. In the area studied in Iran, camels with brucellosis were kept in close contact with other animals. 12 These finding concur with those of our previous study done in Baft, 12 and those of Zowghi and Ebadi, 13 who isolated B. melitensis in several camels in Iran.

In Butana area, Eastern Sudan, where camels are reared together with cattle, sheep and goats, Agab et al. isolated many strains of B. abortus from lymph nodes of camels serologically positive for brucellosis. ${ }^{14}$ In Darfur region, which owns over $25 \%$ of cattle, sheep and goats in Sudan, brucellosis is widely spread in large and small ruminants and camels introduced in the area showed high levels of incidence. 15

The presence of $B$. abortus antibodies in all age groups in this study indicates that the infection starts in the early life probably through sucking. Similar patterns were found in cattle, and Oloffs et al. reported that $30 \%$ of positive animals in Uganda were younger than 3 years. ${ }^{16}$ The high levels of abortions caused by brucellosis and other etiological agents threaten the camel breeding in some parts of Darfur region. ${ }^{17}$ Although other causes of abortion were not investigated, trypanosomosis was speculated to be one of them. Brucellosis in camels seems to display less clinical signs and antibody levels than in cattle, ${ }^{18}$ probably due to a relative resistance of camels to brucel- 
losis. The disease should be controlled by vaccination of camels and primary hosts.

In the Republic of Yemen, the highest prevalence rate was observed in goats (1.3\%) and this was statistically significant when compared with the prevalence rate among other species of animals (0.34\%). ${ }^{7}$

Camel breeding is common in the hot regions of Iran and camels provide part of the fresh milk used locally for human consumption. Infection may develop in people who are frequently in contact with camel herds, or who drink camel milk and its products. Therefore, the number of human brucellosis cases is expected to increase in some part of Iran as long as the disease persists in the animal reservoir. Kiel and Khan reported that the prevalence rates among goats (1.3\%) and sheep $(0.6 \%)$ in Iran were higher than those among goats (0.8\%) and sheep (0.3\%) in Saudi Arabia. 19 However, these were lower than those reported in Omani goats (6.4\%) by another study, ${ }^{20}$ indicating a possible risk factor for Omani camels as well. Radwan et al. reported that brucellosis in camels in central Saudi Arabia appeared to be connected with $B$. melitensis infection of sheep and goats, and

Table 1. Distribution of camels in Qalehgange region, Iran.

\begin{tabular}{lcc} 
Region & $\begin{array}{c}\text { Total camel } \\
\text { in region }\end{array}$ & $\begin{array}{c}\text { Blood } \\
\text { sampled }\end{array}$ \\
Jamshahi & 541 & 516 \\
Rigmiti & 125 & 112 \\
\hline Khargoushi & 214 & 199 \\
Dehgowd & 123 & 117 \\
\hline Jahbagh & 363 & 340 \\
Keshmiran & 323 & 303 \\
\hline Jahnoori & 128 & 103 \\
Jahhasan & 226 & 201 \\
\hline Nowdeg & 283 & 280 \\
Bargah & 157 & 140 \\
\hline Gelashkard & 356 & 330 \\
Rameshk & 135 & 115 \\
\hline Hourpasefid & 28 & 25 \\
Mahroueiyeh & 53 & 47 \\
\hline Bejegan & 412 & 390 \\
Moarez & 237 & 207 \\
\hline Nourabad & 228 & 203 \\
\hline
\end{tabular}

also represents a serious public health risk. ${ }^{21}$ Omar et al. reported that seroprevalence in camels (milk and serum samples) was $37.5 \% .{ }^{9}$ The seroprevalence in males was $28.2 \%$ and in females $40.1 \%$. Twelve (60\%) of the 20 nomads and three (9\%) of the 33 abattoir workers had positive antibody titres.

\section{Conclusions}

This study confirmed the presence of Brucella sp. infection in the Qalehgange region in Iran, showing a significant prevalence rate in camels (7\%). Intervention strategies should include safe breeding procedures, regular serology testing, slaughtering of infected animals and vaccination of uninfected herds of camels.

\section{References}

1. Abbas B, Chabeuf G, Bonnet P, et al. Camel Pastoralism in the Butana and northeast Sudan and interdisciplinary study. Nomadic Peoples 1992;31:64-84.

2. Mayada G, El-Gohary A, Melzer F. Brucellosis in camels. Res Vet Sci (in press).

3. Mohammed 0, Megersa B, Abebe R, et al. Seroprevalence of Brucellosis in Camels in and Around Dire Dawa City, Eastern Ethiopia. J Anim Ve. Adv 2011;10:1177-83.

4. Al-Khalaf S, El-Khaldi A. Brucellosis of camels in Kuwait. Comp Immunol Microbiol Infect Dis 1989;12:1-4.

5. Knoess KH. The camel as a meat and milk animal. World Anim Rev 1977;22:39-44.

6. Cooper CW. Risk factors in transmission of brucellosis from animals to humans in Saudi Arabia. Trans R Soc Trop Med Hyg 1992;86:206-9.

7. Al-Shamahy HA. Seropositivity for brucellosis in a sample of animals in the Republic of Yemen. East Mediterr Health J 1999;5:1035-41.

8. Al-Shamahy HA. The prevalence of Brucella antibodies in Yemen. Saudi Med J 1997;18:45-8.

9. Omar MM, Musa MT, Bakhiet MR, Perret L.
Brucellosis in camels, cattle and humans: associations and evaluation of serological tests used for diagnosis of the disease in certain nomadic localities in Sudan. Rev Sci Tech 2010;29:663-9.

10. Stohr K, Melsin FX. The role of veterinary public health in the prevention of zoonosis. Arch Virol Suppl 1997;13:207-18.

11. Cooper CW. The epidemiology of human brucellosis in a well defined urban population in Saudi Arabia. J Trop Med Hyg 1991;94:416-22.

12. Rafieipour A, Ziaei N. 2007. Brucellosis in camels in Iran. Vet On-line Available from: http://priory.com/vet/Brucellosis_in_camel s.htm

13. Zowghi E, Ebadi A. Brucellosis in camels in Iran. Rev Sci Tech 1988;7:383-6.

14. Agab H, Abbas B, el Jack Ahmed H, Mamon IE. 1994. First report on the isolation of Brucella abortus biovar 3 from camel (Camelus dromedarius) in Sudan. Rev Elev Med Vet Pays Trop 1994;47:361-3.

15. Mousa MT. Brucellosis in Darfur States: The magnitude of the problem and methods of diagnosis and control of the disease. PhD Thesis, University of Khartoum, Sudan, 1995.

16. Oloffs A, Baumann MPO, Afema J, Nakavuma J. Experiences with a strategy to investigate bovine brucellosis in a rural area in Southwest Uganda. Rev Elev Med Vet Pays Trop 1998;51:101-5.

17. Musa M, Shigidi MTA. Brucellosis in Camels in Intensive Animal Breeding Areas of Sudan. Implications in Abortion and Early-Life Infections. Rev Elev Med Vet Pays Trop 2001;54:11-5.

18. Mousa AM, Elhag KM, Hogali M, Sugathan TN1987. Brucellosis in Kuwait: a clinicoepidemiological study. Trans R Soc Trop Med Hyg 1987;81:1020-1.

19. Kiel FW, Khan MY. Brucellosis in Saudi Arabia. Soc Sci Med 1989;29:999-1001.

20. Mehta FR, El-Mauly KN. 1990. Is brucellosis a public health problem in Oman? Medical Newsletter 1990;6:11-4.

21. Radwan AI, Bekairi SI, Prasad PVS. Serological and bacteriological study of brucellosis in camels in central Saudi Arabia. Rev Sci Tech 1992;11:837-44. 